\title{
Zinc Status in South Asian Populations-An Update
}

\author{
Saeed Akhtar \\ Department of Food Science and Technology, Bahauddin Zakariya University, Multan, Pakistan
}

\begin{abstract}
This article attempts to highlight the prevalence of zinc deficiency and its health and economic consequences in South Asian developing countries and to shed light on possible approaches to combating zinc deficiency. A computer-based search was performed on PubMed, Google, and ScienceDirect.com to retrieve relevant scientific literature published between 2000 and 2012. The search yielded 194 articles, of which 71 were culled. Studies were further screened on the basis of population groups, age and sex, pregnancy, and lactation. The most relevant articles were included in the review. Cutoffs for serum zinc concentration defined for zinc deficiency were $65 \mu \mathrm{g} / \mathrm{dL}$ for males and females aged $<10$ years, $66 \mu \mathrm{g} / \mathrm{dL}$ for non-pregnant females, and $70 \mu \mathrm{g} / \mathrm{dL}$ for males aged $\geq 10$ years. Population segments from rural and urban areas of South Asian developing countries were included in the analysis. They comprised pregnant and lactating women, preschool and school children. The analysis reveals that zinc deficiency is high among children, pregnant and lactating women in India, Pakistan, Bangladesh, Sri Lanka, and Nepal. Diarrhoea has been established as a leading cause to intensify zinc deficiency in Bangladesh. Little has been done in Sri Lanka and Nepal to estimate the prevalence of zinc deficiency precisely. A substantial population segment of the South Asian developing countries is predisposed to zinc deficiency which is further provoked by increased requirements for zinc under certain physiological conditions. Supplementation, fortification, and dietary diversification are the most viable strategies to enhancing zinc status among various population groups.
\end{abstract}

Key words: Growth; Infections; Malnutrition; Zinc; South Asia

\section{INTRODUCTION}

Zinc plays a critical role in normal functioning of body and is integrated with several enzyme systems. Gene expression, cell division, immunity, and reproduction are important biological functions of zinc (1). Adequate dietary intake of zinc has been shown to exert ameliorating effect on the skin, and this attenuates the likelihood of restricted linear growth in young children. Neurobehavioural disturbances among infants, hypoguesia, the chronic non-healing leg ulcers and repeated infections are common among zinc-deficient subjects of all ages. Pregnant women with zinc deficiency are at the risk of complicated pregnancy outcomes (2-4).

Correspondence and reprint requests:

Dr. Saeed Akhtar

Department of Food Science and Technology

Bahauddin Zakariya University

Multan 60800, Pakistan

Email: saeedbzu@yahoo.com

Fax: +92619210269
Predictably, half of the global population is at the risk of low intakes of zinc. Around 800,000 deaths among children below 5 years of age occur annually due to diarrhoea $(176,000)$, pneumonia $(406,000)$, and malaria $(207,000)$. High mortality rate among children resulting from these infections has been reported to be associated with inadequate zinc intake. The loss incurred due to zinc deficiency amounts to nearly 16 million global disability-adjusted life years (DALYs) (5-7).

Prevalence of zinc deficiency in developing countries is very common, and $61 \%$ of the population is at an increased risk of low dietary zinc intake (8). Almost $4 \%$ of child mortality and DALYs have been associated with zinc deficiency (5). Studies demonstrated that $49.4 \%$ of adolescent girls in Delhi (9) and 52\% non-pregnant women of central India $(10,11)$ suffered from zinc deficiency. There is a paucity of literature to reflect zinc deficiency in Pakistan. However, limited studies reported 54.2\% children and $37.1 \%$ preschool children to be zinc- 
deficient $(12,13)$. Malnutrition and poverty in Bangladesh are the leading causes of high rate of zinc deficiency, especially at early pregnancies (14). Similarly, zinc deficiency is prevalent among various population groups in Sri Lanka, especially among preschool children and adolescents (15). Prevalence of zinc deficiency among non-pregnant Nepalese women was attributed to excessive use of phytaterich foods with limited dietary zinc intakes (16).

Although zinc was omitted from micronutrient priority list of the United Nations in 1999, compelling evidence exists to suggest a global realization on health benefits of zinc nutrition in the last decade. Zinc deficiency, as a public-health problem, is now recognized among the South Asian developing economies. Despite this recent recognition, rigorous efforts are not underway to reduce the gravity of the problem. Currently, no precise data on the extent of prevalence of zinc deficiency are available at the national level; hence, it is the proper time to assess the severity of the risk of zinc deficiency in South Asian populations. Although several international organizations, such as International Zinc Nutrition Consultative Group (IZiNCG), Micronutrient Initiatives (MI), Food and Agriculture Organization (FAO), World Health Organization (WHO), Global Alliance for Improved Nutrition (GAIN), Sharing United States Technology to Aid in the Improvement of Nutrition (SUSTAIN), and United Nations International Children's Emergency Fund (UNICEF), have been perpetually working in the developing countries to improve nutritional status of the vulnerable populations, the outcome of these efforts has not yet knocked any mitigating effect on the prevalence of zinc deficiency among the predisposed population groups. A plausible explanation for inefficacy of these efforts is the prevalence of poverty, illiteracy, lack of infrastructure, and government priorities to eliminate hidden hunger in the region.

This review highlights current situation of zinc deficiency in South Asian developing countries and examines causes of zinc deficiency, adverse health effects, and possible intervention strategies in India, Pakistan, Bangladesh, Sri Lanka, and Nepal. Future directions have been provided to delineate the action-oriented strategies and plans that need to acquire momentum for virtual elimination of zinc deficiency in this region.

\section{Zinc deficiency in South Asian developing countries}

Sufficient data are available to estimate the extent of zinc deficiency in South Asian developing countries. Data obtained through national nutrition surveys, small representative epidemiological studies, complete randomized trials (CRTs), and meta-analyses illustrate the severity of zinc deficiency in South Asian societies. A plethora of publications in the literature is, however, available to address issues relating to zinc nutrition in westernized world, and two complete reviews $(1,17)$ gained wider recognition worldwide to establish zinc deficiency as a public-health problem. Amongst several other instrumental determinants, low dietary intake, low bioavailability, unhygienic conditions, recurrent infections, poor socioeconomic status, unstable political situation, improper priority setting in national agenda, inappropriate monitoring, inadequate surveillance, and lack of public awareness have been identified as leading causes of high prevalence of zinc deficiency in low-income South Asian countries.

\section{Zinc deficiency in India}

India, with its population of 1.2 billion, is ranked $2^{\text {nd }}$ in the world for the number of children (47\%) suffering from malnutrition and $15^{\text {th }}$ amongst leading countries with hunger situation. About 2.1 million deaths among Indian children ( $<5$ years) occur every year because of diarrhoea, typhoid, malaria, measles, and pneumonia. Evidently, 1,000 children die each day for diarrhoea alone $(18,19)$.

Reliable national-level data are scant to clearly demonstrate the extent of the prevalence of zinc deficiency. However, numerous small studies highlight the likelihood of widespread marginal zinc deficiency among children and pregnant women in India. Recent epidemiological studies have confirmed high prevalence of zinc deficiency among children belonging to low socioeconomic groups in five major Indian states, reporting an overall zinc deficiency of $43.8 \%$ (cutoff level $\leq 65 \mu \mathrm{g} / \mathrm{dL}$ ), with the highest in Orissa $(51.3 \%)$, followed by Uttar Pradesh (48.1\%), Gujarat (44.2\%), Madhya Pradesh (38.9\%), and Karnataka (36.2\%). Table 1 indicates the distribution of children based on serum zinc levels of $<55 \mu \mathrm{g} / \mathrm{dL},<60 \mu \mathrm{g} / \mathrm{dL}$, and $<65$ $\mu \mathrm{g} / \mathrm{dL}(11,20)$. One more recent cross-sectional study ( $\mathrm{n}=630$ ) confirmed low plasma zinc concentration and poor cognitive performance in $45 \%$ of the adolescent girls in India, signifying the need to adopt dietary zinc intake for normal health (21). Nearly $64.6 \%$ of the pregnant women have been shown to suffer from zinc deficiency in the state of Haryana because of low dietary intake of zinc. Similarly, a high prevalence of zinc deficiency (41\%) has been reported among the nulliparous 


\begin{tabular}{|lccc|}
\hline \multicolumn{3}{|l|}{ Table 1. Distribution of children below five years of age in India according to their serum zinc levels } \\
\hline \multirow{2}{*}{ State } & \multicolumn{3}{c|}{ Serum zinc levels } \\
\cline { 2 - 4 } & $<55 \mu \mathrm{g} / \mathrm{dL}$ & $<60 \mu \mathrm{g} / \mathrm{dL}$ & $<65 \mu \mathrm{g} / \mathrm{dL}$ \\
\hline Gujarat (n=353) & 25.8 & 34.0 & 44.2 \\
Karnataka (n=356) & 19.1 & 26.4 & 36.2 \\
Madhya Pradesh (n=285) & 14.7 & 22.8 & 38.9 \\
Orissa (n=345) & 34.5 & 43.2 & 51.3 \\
Uttar Pradesh (n=316) & 29.4 & 40.2 & 48.1 \\
Total (n=1655) & 25.0 & 33.5 & 43.8 \\
\hline Derived from Kapil and Jain 2011 (11) & \multicolumn{3}{|}{} \\
\hline
\end{tabular}

non-pregnant women in India $(22,23)$. Current zinc status of various population groups in India warrants the need to undertake multicentre studies, more rigorous analyses, and extensive surveys to identify the factors leading to zinc deficiency. More efforts are needed to estimate the magnitude of zinc deficiency among population groups and to devise strategies to combating this nutritional problem in India.

\section{Zinc deficiency in Pakistan}

Estimates indicate infant and maternal mortality rates to be 73 per 1,000 livebirths (24) and 276 per 100,000 livebirths (25) respectively in Pakistan. Several studies revealed zinc deficiency to be prevalent among schoolgoing children (54.2\%) and preschool children (37.1\%) in Pakistan. Pregnant women (54\%) were also shown to suffer from zinc deficiency in Sindh province of Pakistan, and 50\% of the participating subjects in another study manifested low plasma levels of zinc, suggesting marginal zinc deficiency among Pakistani population $(12,13)$. Prevalence of zinc deficiency in pregnant and nonpregnant women in Pakistan has been presented in Table 2 (26).

Diarrhoea, pneumonia, and malaria are closely associated with zinc deficiency $(27,28)$; therefore, zinc supplementation and fortification have been recommended as potential approaches to combating zinc deficiency in Pakistan (29). Nutritional programmes for preventive zinc supplementation for children below 5 years of age have been suggested for inclusion in the national strategies to reducing zinc deficiency (30). Moreover, addition of zinc fortificants in wheat flour-the main dietary staple of the Pakistani population-is a focus of the policy-makers and flour industry to control zinc deficiency in the country (31). However, such addition of fortificants in wheat flour needs to be critically evaluated for the forms of fortificants and fortification levels to ensure the undamaging health effects of these compounds (32).

\section{Zinc deficiency in Sri Lanka}

There have been fewer reports on magnitude of the prevalence of zinc deficiency in Sri Lanka. Reports to assess the gravity of prevalence of zinc deficiency at the national level are not available for Sri Lanka. However, several small studies $(33,34)$ confirmed low serum zinc concentrations (cutoff serum zinc $<65 \mu \mathrm{g} / \mathrm{dL}$ ) in Sri Lankan populations. Nearly $57.0 \%$ male and $50.0 \%$ female preschool children were found to be zinc-deficient. Information derived from 24-hour dietary recall of these children validated that their zinc intake was only half of the RDA due to inadequate consumption of foods of animal origin (34). Another study demonstrated that $51.5 \%$ of adolescent males and $58.3 \%$ females were affected by zinc deficiency (serum zinc $<65.032 \mu \mathrm{g} / \mathrm{dL}$ ) (35). Low intakes of foods of ani-

Table 2. Zinc deficiency in pregnant and non-pregnant women in Pakistan (2011)

\begin{tabular}{|lccccccc|}
\hline \multirow{2}{*}{ Area } & \multicolumn{3}{c}{ Non-pregnant women } & & \multicolumn{3}{c|}{ Pregnant women } \\
\cline { 2 - 3 } & $\begin{array}{c}\text { Deficient } \\
(<60 \mu \mathrm{g} / \mathrm{dL})\end{array}$ & $\begin{array}{c}\text { Non-deficient } \\
(\geq 60 \mu \mathrm{g} / \mathrm{dL})\end{array}$ & $\mathrm{N}$ & & $\begin{array}{c}\text { Deficient } \\
(<60 \mu \mathrm{g} / \mathrm{dL})\end{array}$ & $\begin{array}{c}\text { Non-deficient } \\
(\geq 60 \mu \mathrm{g} / \mathrm{dL})\end{array}$ & $\mathrm{N}$ \\
Total & 41.6 & 58.4 & 5,953 & & 48.3 & 51.7 & 791 \\
Urban & 38.2 & 61.8 & 2,395 & & 47.2 & 52.8 & 285 \\
Rural & 43.2 & 56.8 & 3,558 & & 48.7 & 51.3 & 506 \\
\hline \multicolumn{4}{l}{ Derived from National Nutrition Survey Report (NNS) (26); N=Total no. of subjects } \\
\hline
\end{tabular}


mal origin and low bioavailability of zinc in plantbased diets have been attributed to high prevalence of zinc deficiency.

\section{Zinc deficiency in Bangladesh}

A recent study showed $41 \%, 35 \%$, and $18 \%$ of the total subjects under study to be stunted, underweight, and wasted respectively while 16\%, 11.5\%, and 3\% were severely stunted, underweight, and wasted respectively in rural Bangladesh (36). Primarily, two fundamental indicators are used in estimating the prevalence of zinc deficiency among vulnerable population groups, i.e. stunting and inadequacy of zinc intake. Higher stunting rate (43\%) was noted among children below 5 years of age, suggesting zinc deficiency to be extensively prevalent in Bangladesh (5). Zinc deficiency is more existent in communities consuming restricted meat-based diets and increased amount of vegetables containing more phytates.

Diarrhoea is regarded a fundamental cause of child deaths in Bangladesh, and zinc supplementation can reduce morbidity and mortality by preventing 30,000 to 75,000 childhood deaths $(14,37,38)$. Another study elucidated that a 5-day course of zinc treatment exerted the same influence as that of a 10-day course to prevent diarrhoea over the 3 months following treatment of a diarrhoeal episode (Table 3) (39). Zinc supplementation resulted in $15 \%$ less incidence of diarrhoea, thus saving the lives of 30,000-75,000 children per year. A reduction of $15 \%$ in the illness duration and $16 \%$ reduction in the likelihood of disease progression were observed as a positive effect of zinc supplementation in Bangladesh $(40,41)$.
Several rudimentary issues have been identified that hamper the accomplishment of challenging task of promoting better nutrition in Bangladesh. Government priority to scale up sustainable micronutrient interventions and capacity-building at local and national levels to implement these interventions are currently lacking and require a momentous leap to address this nutritional issue. Moreover, there is a dire need to chalk out plans and policies to curb poverty through the promotion of entrepreneurship, agriculture-based cottage industry, and fisheries in the region.

\section{Zinc deficiency in Nepal}

Nepal, as one of the world's poorest countries and the poorest in South Asia, witnesses infant mortality to be 96 per 1,000 livebirths. Poverty remains a substantial impediment to ensure the supply of sufficient balanced food to the population. Around 500 non-pregnant Nepalese women, examined for plasma zinc concentration, exhibited elevated zinc deficiency. Zinc deficiency was more common among women of childbearing age. Similarly, zinc deficiency has been shown to be the major cause of poor newborn's health and poor host defense against infections in Nepal (16). Pregnant women in Nepal are more vulnerable to multiple micronutrient deficiencies. Among 1,165 pregnant women in rural Nepal, 61\% demonstrated higher prevalence of micronutrient deficiencies, including that for zinc (42).

Beneficial effects of zinc supplementation have been seen on child growth, particularly among vulnerable groups (43). Moreover, multiple micronutrients reduced the burden of zinc deficiency in

\begin{tabular}{|c|c|c|}
\hline \multirow{2}{*}{ Characteristics } & \multicolumn{2}{|c|}{ Zinc treatment group } \\
\hline & 5 days $(\mathrm{N}=803)$ & 10 days $(\mathrm{N}=819)$ \\
\hline Age (months) & $25.6 \pm 16.2$ & $25.6 \pm 16.2$ \\
\hline \multicolumn{3}{|l|}{ z-scores } \\
\hline Weight-for-height & $-0.73 \pm 1.0$ & $-0.66 \pm 1.0$ \\
\hline Height-for-age & $-2.17 \pm 1.2$ & $-2.11 \pm 1.1$ \\
\hline Weight-for-age & $-1.78 \pm 1.0$ & $-1.68 \pm 1.0$ \\
\hline Maternal education (years) & $5.8 \pm 2.7$ & $6.1 \pm 2.7$ \\
\hline Family-size (persons) & $6.1 \pm 2.3$ & $6.0 \pm 2.2$ \\
\hline Sex (male) $(\%)$ & 50.8 & 48.7 \\
\hline Tubewell (drinking-water) (\%) & 98.4 & 97.9 \\
\hline Sanitary latrine (\%) & 21.8 & 19.7 \\
\hline
\end{tabular}


rural Nepal (44). By contrast with the foregoing results indicating beneficial effects of micronutrient supplementation, daily supplementation to young children with zinc alone and/or with other micronutrients in Southern Nepal depicted no effect on mortality rate among infants. However, they had a protective effect against diarrhoea, dysentery, and acute respiratory illness $(45,46)$. Likewise, zinc and multiple micronutrients did not indicate any additional beneficial effect on improving maternal haematologic status during pregnancy $(47,48)$.

Apparently, the existing infrastructure and health service system in Nepal need to be completely revamped to ensure safe and nutritious food supply to the population. This seems much challenging in the absence of good governance, international support, and development of awareness among the stakeholders.

\section{Aetiology of zinc deficiency}

Zinc nutrition had been a neglected area in developing countries; nevertheless, a wave of realization on the health significance of zinc spurred in early 2000, and investigations were initiated to explore the causes of zinc deficiency. Extent of the prevalence of stunting and inadequacy of zinc in the diets had been the markers of estimating zinc deficiency $(1,49)$. Several studies confirmed inadequate intake of zinc to be one of the most significant determinants for the development of zinc deficiency (50). Amongst other leading factors that develop zinc deficiency, elevated zinc requirements, poor absorption, increased losses, and impaired utilization of zinc by the body are also important in playing a vital role. A strong association between the consumption of plant-based diets and zinc deficiency in developing countries has been widely reported (51). High phytic acid content in Asian diets, especially cereals and cereal-based diets, forms zinc-phytic acid complexes in the intestine (52) and markedly inhibits intestinal absorption of zinc $(53,54)$. Bioavailability of zinc is greatly influenced in the presence of several other inhibitors (53), including calcium and polyphenols (55). Table 4 presents the physiologic requirements for absorbed zinc during childhood by age-group and sex and during pregnancy and lactation (56).

Decreased tendency among mothers for breastfeeding normally limits an optimal zinc supply to the infants. Similarly, need for zinc during pregnancy increases, especially among women with low plasma zinc, to meet foetal and maternal requirements (57). One group of researchers explicated that the

\begin{tabular}{|lcc|}
\hline $\begin{array}{c}\text { Table 4. Estimated physiologic requirements for } \\
\text { absorbed zinc during childhood by age- } \\
\text { group and sex and during pregnancy } \\
\text { and lactation }\end{array}$ \\
\hline Age, sex, stage & $\begin{array}{c}\text { Reference } \\
\text { weight (kg) }\end{array}$ & $\begin{array}{c}\text { Physiologic } \\
\text { requirement } \\
\text { (mg/day) }\end{array}$ \\
\hline 6-<12 months & 9 & 0.84 \\
1-<3 years & 12 & 0.83 \\
3-<6 years & 17 & 0.97 \\
6-10 years & 25 & 1.12 \\
\hline 10-12 years, M & 35 & 1.40 \\
10-12 years, F & 37 & 1.26 \\
12-15 years, M & 48 & 1.82 \\
12-15 years, F & 48 & 1.55 \\
15-18 years, M & 64 & 1.97 \\
15-18 years, F & 55 & 1.54 \\
\hline At pregnancy & - & 2.27 \\
During lactation & - & 2.89 \\
\hline Derived from WHO 1996 (56) & \\
\hline
\end{tabular}

requirement for zinc is boosted up during the early months of pregnancy. Therefore, zinc absorption is likely to increase at this stage (58). This condition is aggravated in instances where recurrent reproductive cycling takes place, and mothers are highly disposed to zinc deficiency (59).

Sufficient body of literature supports diarrhoea as a potent cause of zinc deficiency among population groups living in developing countries. The risk of zinc deficiency multiplies during diarrhoea and is associated with gross losses of zinc through the faeces $(60,61)$. Zinc has been found to have a therapeutic benefit in acute and persistent diarrhoea and may also reduce infant mortality (62.63).

Health and economic consequences of zinc deficiency

Shigellosis, Campylobacteriosis, E. coli infection, Staphylococcus aureus infection, salmonellosis, listeriosis, and cholera have been shown to heighten the disease burden and exert a damaging effect on human health in underdeveloped communities $(64,65)$. Widely-reported incidences of such infections, especially among children in developing world, are not the direct outcomes of zinc deficiency. However, the likelihood of these incidences is reduced to certain extent through zinc therapy (66). There is mounting evidence to support the role of zinc in linear growth and weight gain (67). Premature delivery and low birthweight of babies 
have been the known outcomes of zinc deficiency in mothers, leading to restricted zinc supply to the foetus (2). In total, an estimate has confirmed 800,000 childhood deaths annually due to zinc deficiency. These deaths and increased morbidity are associated with infectious diseases, resulting in $1.9 \%$ of global DALYs. Another group of researchers explored high mortality rate among children, signifying 10.8 million deaths annually in the world. Predominant health outcomes of zinc deficiency include short stature, impaired immune function, and other disorders, like respiratory infections, malaria, and diarrhoeal diseases $(68,69)$.

Zinc deficiency exerts greater influence on mortality rates, causing $2.7 \%$ of global DALYs compared to around $6 \%$ caused by iron deficiency. Low- and middle-income developing countries are the largest victims of zinc deficiency as it negatively impacts the health and leads to disabilities, such as cognitive impairment and decreased work-capacity (70).

\section{Current strategies to combating zinc deficiency}

Supplementation, fortification, and dietary diversification are the most viable strategies to enhancing zinc status among various population groups. To implement these strategies successfully, a thorough knowledge of food constituents, chemical composition of supplements or fortificants and their bioavailability is considerably important (71). It seems more practicable to practise supplementation by integrating it with ongoing national programmes for health and nutrition. These approaches can be more effective among population groups with increased awareness on the deleterious health effects of zinc and related sequelae. The strategies must also be well-coordinated among government, education, public health and industry sectors, international organizations, and consumer groups.

\section{Supplementation}

Zinc supplementation has been widely practised in the majority of South Asian poorer economies. However, there is a significant heterogeneity in the results of various studies. This strategy holds certain advantages over others, like rapid improvement in zinc status, easy administration, individual compliance, and being equally applicable for all agegroups (1). Viability of zinc supplementation programmes in developing countries, as a defensive approach against diarrhoea, pneumonia, respiratory tract infection, restricted growth, and mortality, is widely-documented in the literature. Several studies demonstrated an increase in linear growth and weight gain attributable to zinc supplementation among children in developing countries (72). Zinc supplementation has been extensively employed in Bangladesh, and dramatic reductions in the occurrence of persistent diarrhoea and severe acute lower respiratory infections were witnessed (73-75). In reality, no planned national-level zinc supplementation programmes have been launched in most of the South Asian developing countries. Huge investments, economic and social reforms, poverty alleviation, and coordinated awareness programmes are significant determinants to shape nations' future in terms of health and economic well-being of the populations.

\section{Food fortification}

Food fortification has been widely-debated as a potential approach to combating micronutrient deficiencies in developing countries. Seemingly, there is a great diversity for the success and failure of this strategy in the developing world. South Asian low-income countries are still far away to reap the fruit of this strategy as poverty has been the most significant determinant of failure. There are several other underlying determinants that impact the successful implementation of fortification programmes critically in these regions, including government commitment, legislation, education, awareness, and cost of fortification. Zinc fortification in South Asian developing countries is not yet well-structured despite the fact that it showed a positive effect on total zinc absorption and enhanced zinc status in populations $(2,76)$.

According to World Health Organization, food fortification is a viable approach in lower-income countries, and its impact on target population's nutrient intake is promising (77). Cereals and cereal products are the commonly-consumed foods in South Asian developing countries. Therefore, zinc fortification in cereal products would have a positive impact on serum zinc concentration (78).

There are several technical considerations for zinc fortification programmes, including selection of the food vehicle(s), selection of the form of zinc fortificants, determining the level of zinc fortificants, and cost of fortification programmes (32).

Biofortification is another approach to curbing micronutrient deficiencies in developing countries. This intervention involves agricultural, agronomic, or genetic means to boost up the level of particular micronutrient in the crop. Currently, this technology is being focused to elevate the zinc, iron, and 
pro-vitamin A carotenoid levels in some of the world's most important staple food-crops, i.e. rice, wheat, and maize (79).

\section{Dietary diversification}

Emphasis has been laid down in the literature to adopt food dietary diversification as a preventive strategy to curtail the gravity of micronutrients deficiency. Dietary diversification employs consumption of meat, poultry or fish, and all good sources of readily-available zinc (80). Selection of foods, modification in traditional methods of food preparation and focused food production are a few important considerations for adequate zinc supply through this approach. For example, phytate contents in cereals and legumes would be reduced by enzymatic hydrolysis of phytic acid and by germination and fermentation process. Similarly, antinutrients, such as saponins and polyphenols, can also be minimized through soaking for enhanced zinc absorption $(53,81)$. Furthermore, this approach is particularly beneficial to improve bioavailability of iron, vitamin $B_{12}$, vitamin $A$, and calcium (82). This strategy holds a great potential for being economical, sustainable, and culturally acceptable in developing countries.

\section{Future directions}

Zinc deficiency is now a public-health problem, especially in South Asian developing economies. Apparently, no policy seems to exist for combating the issue and reaching an equitable and sustainable solution. Similarly, no strategy would be successful in the absence of reliable data, precisely showing the magnitude of the prevalence of zinc deficiency in South Asia. In most of the studies and surveys carried out so far in the developing countries to gauge the zinc status, the sample-sizes had been too small to yield results that could be applied to the whole population. Thus, the nutrition survey mechanism needs to be revitalized to cover the whole population for consistent results. Several previous efforts to elevate zinc status among vulnerable groups revealed that the communities did not show tendency to receive the supplementation, rather the conventional pharmacological treatment for rapid relief was considered more acceptable. Therefore, creating awareness through all means and sources would have an encouraging impact in reducing zinc deficiency in the poorer settings. Compelling scientific evidence suggests a number of approaches to making supplementation programmes successful. These include combining supplementation with oral rehydration salt
(ORS) for the management of diarrhoea, preparation of appropriate zinc formulations, training/ education, consistent availability of zinc products, and monitoring and evaluation. Industry, governments, donors, and consumers are the major drivers for the success of national nutrition programmes. Additionally, targeted supplementation, fortification, and dietary strategies need to be focused to alleviate the likelihood of zinc deficiency in South Asian developing countries. This needs to be associated with strong advocacy, political commitment, a precise infrastructure, financial investment, and capacity-building to implement such programmes. Evidently, more studies in developing countries are needed to evaluate the current nutritional status of the populations critically and to achieve the Millennium Development Goals for health, the core idea of which is to improve maternal and child health.

\section{Conclusions}

Zinc deficiency in South Asian developing countries is considerably prevalent. In retrospect, Bangladesh seems to have the highest prevalence of zinc deficiency. Populations from India, Nepal, Sri Lanka, and Pakistan are also affected by zinc deficiency. Inadequate intake of zinc has been regarded as one of the most significant causes of zinc deficiency. Diarrhoea, respiratory infections, and malaria have been associated with zinc deficiency, particularly in low-income developing countries. Supplementation, fortification, and dietary diversification are the most viable strategies to enhancing the zinc status among various population groups. Food fortification is increasingly recognized as an effective approach to improving a population's micronutrient status. Dietary diversification employs consumption of meat, poultry or fish, and all good sources of readily-available zinc and is considered a potential preventive approach to reducing zinc deficiency. Zinc supplementation has been widely practised in majority of these countries. These strategies need to be harmonized in a sociocultural perspective and must be coordinated in developing countries at the national level. Evidently, development of awareness among the vulnerable populations has shown promise to mitigate the devastating impact of this nutritional deficiency.

\section{REFERENCES}

1. Brown KH, Rivera JA, Bhutta Z, Gibson RS, King JC, Lönnerdal B et al.; International Zinc Nutrition Consultative Group (IZiNCG). Assessment of the risk of 
zinc deficiency in populations and options for its control. Food Nutr Bull 2004;25(Suppl 2):S99-203. (IZiNCG Technical document no.1)

2. Hess SY, King JC. Effects of maternal zinc supplementation on pregnancy and lactation outcomes. Food Nutr Bull 2009;30(Suppl 1):S60-78.

3. Kohn S, Kohn D, Schiller D. Effect of zinc supplementation on epidermal Langerhans' cells of elderly patients with decubital ulcers. J Dermatol 2000;27:258-63.

4. Donangelo CM, King JC. Maternal zinc intakes and homeostatic adjustments during pregnancy and lactation. Nutrients 2012;4:782-98.

5. Black RE, Allen LH, Bhutta ZA, Caulfield LE, de Onis $\mathrm{M}$, Ezzati $\mathrm{M}$ et al. Maternal and child undernutrition: global and regional exposures and health consequences. Lancet 2008;371:243-60.

6. Brown KH, Wuehler SE, Peerson JM. The importance of zinc in human nutrition and estimation of the global prevalence of zinc deficiency. Food Nutr Bull 2001;22:113-25.

7. Caulfield LE, Black RE. Zinc deficiency. In: Ezzati M, Lopez AD, Rodgers A, Murray CJL, editors. Comparative quantification of health risks: global and regional burden of disease attributable to selected major risk factors. V. 1. Geneva: World Health Organization, 2004:257-79.

8. Brown $\mathrm{KH}$, Wuehler SE. Zinc and human health: results of recent trials and implications for program interventions and research. Ottawa: Micronutrient Initiative, 2000. $69 \mathrm{p}$.

9. Kapil U, Toteja GS, Rao S, Pandey RM. Zinc deficiency amongst adolescents in Delhi. Indian Pediatr 2011;48:981-2.

10. Menon KC, Skeaff SA, Thomson CD, Gray AR, Ferguson EL, Zodpey $\mathrm{S}$ et al. Concurrent micronutrient deficiencies are prevalent in nonpregnant rural and tribal women from central India. Nutrition 2011;27:496-502.

11. Kapil U, Jain K. Magnitude of zinc deficiency amongst under five children in India. Indian J Pediatr 2011;78:1069-72.

12. Ejaz MS, Latif N. Stunting and micronutrient deficiencies in malnourished children. J Pak Med Assoc 2010;60:543-7.

13. Bhutta ZA. Iron and zinc intake from complementary foods: some issues from Pakistan. Pediatrics 2000;106:1295-7.

14. Ahmed T, Mahfuz M, Ireen S, Ahmed AMS, Rahman $\mathrm{S}$, Islam MM et al. Nutrition of children and women in Bangladesh: trends and directions for the future. $J$ Health Popul Nutr 2012;30:1-11.
15. Hettiarachchi M, Liyanage C. Coexisting micronutrient deficiencies among Sri Lankan pre-school children: a community-based study. Matern Child Nutr 2012;8:259-66.

16. Chandyo RK, Strand TA, Mathisen M, Ulak M, Adhikari RK, Bolann BJ et al. Zinc deficiency is common among healthy women of reproductive age in Bhaktapur, Nepal. J Nutr 2009;139:594-7.

17. Hess SY, Brown KH. Impact of zinc fortification on zinc nutrition. Food Nutr Bull 2009;30(Suppl 1):S79 107.

18. International Food Policy Research Institute. Global hunger index. The challenge of hunger: taming price spikes and excessive food price volatility. Washington, DC: International Food Policy Research Institute, 2011. 59 p. (http://www.ifpri.org/sites/default/ files/publications/ghi11.pdf, accessed on September 2012).

19. World Bank (2009). (http://web.worldbank.org/ WBSITE/EXTERNAL/COUNTRIES/SOUTHASIAE XT/0,,contentMDK:20916955 pagePK:146736 piPK:146830 theSitePK:223547,00.html, accessed on 10 September 2012).

20. Shah D. Magnitude of zinc deficiency and efficacy of zinc. Indian J Pediatr 2011;78:1140-1.

21. Kawade R. Zinc status and its association with the health of adolescents: a review of studies in India. Glob Health Action 2012;5:7353. (DOI: 10.3402/gha. v5i0.7353).

22. Pathak P, Kapil U, Dwivedi SN, Singh R. Serum zinc levels amongst pregnant women in a rural block of Haryana State, India. Asia Pac J Clin Nutr 2008;17:276-9.

23. Pathak P, Kapil U, Kapoor SK, Dwivedi SN, Singh R. Magnitude of zinc deficiency among nulliparous nonpregnant women in a rural community of Haryana State, India. Food Nutr Bull 2003;24:368-71.

24. United Nations Children's Fund. The state of the world's children 2008: child survival. New York, NY: United Nations Children's Fund, 2007. 154 p.

25. Khan MA, Gilbert C, Khan MD, Qureshi MB, Ahmad $\mathrm{K}$. Incidence of blinding vitamin A deficiency in North West Frontier Province and its adjoining federally administered tribal areas, Pakistan. Ophthalmic Epidemiol 2009;16:2-7.

26. Pakistan. Government of Pakistan. National nutrition survey Pakistan 2011. Islamabad: Nutrition Wing, Cabinet Division, Government of Pakistan, 2011. 105 p.

27. Raza N, Khan DA. Zinc deficiency in patients with persistent viral warts. J Coll Physicians Surg Pak 2010;20:83-6.

28. Yakoob MY, Bhutta ZA. Effect of routine iron supplementation with or without folic acid on anemia during 
pregnancy. BMC Public Health 2011;11(Suppl 3):S21.

29. Yakoob MY, Theodoratou E, Jabeen A, Imdad A, Eisele $\mathrm{TP}$, Ferguson $\mathrm{J}$ et al. Preventive zinc supplementation in developing countries: impact on mortality and morbidity due to diarrhea, pneumonia and malaria. BMC Public Health 2011;11(Suppl 3):S23.

30. Imdad A, Bhutta ZA. Effect of preventive zinc supplementation on linear growth in children under 5 years of age in developing countries: a meta-analysis of studies for input to the lives saved tool. BMC Public Health 2011;11(Suppl 3):S22.

31. Akhtar S, Asghar A. Mineral fortification of whole wheat flour: an overview. In: Preedy VR, Watson RR, Patel VB, editors. Flour and breads and their fortification in health and disease prevention. London: Academic Press, 2011:263-71.

32. Akhtar S, Anjum FM, Rehman ZU, Sultan MT, Riaz M, Ahmed A. Effect of mineral fortification on plasma biochemical profile in rats. Biol Trace Elem Res 2011;143:1594-606.

33. Hettiarachchi M, Liyanage $C$, Wickremasinghe $R$, Hilmers DC, Abrams SA. The efficacy of micronutrient supplementation in reducing the prevalence of anaemia and deficiencies of zinc and iron among adolescents in Sri Lanka. Eur J Clin Nutr 2008;62:85665.

34. Hettiarachchi M, Liyanage C. Coexisting micronutrient deficiencies among Sri Lankan pre-school children: a community-based study. Matern Child Nutr 2012;8:259-66.

35. Hettiarachchi M, Liyanage C, Wickremasinghe R, Hilmers DC, Abrahams SA. Prevalence and severity of micronutrient deficiency: a cross-sectional study among adolescents in Sri Lanka. Asia Pac J Clin Nutr 2006;15:56-63.

36. Ahmed AM, Ahmed T, Roy SK, Alam N, Hossain MI. Determinants of undernutrition in children under 2 years of age from rural Bangladesh. Indian Pediatr 2012;49:821-4.

37. Baqui AH, Zaman K, Persson LA, El Arifeen S, Yunus $\mathrm{M}$, Begum $\mathrm{N}$ et al. Simultaneous weekly supplementation of iron and zinc is associated with lower morbidity due to diarrhea and acute lower respiratory infection in Bangladeshi infants. J Nutr 2003;133:4150-7.

38. Darmstadt GL, Osendarp SJ, Ahmed S, Feldman C, Van Raaij JM, Baqui AH et al. Effect of antenatal zinc supplementation on impetigo in infants in Bangladesh. Pediatr Infect Dis J 2012;31:407-9.

39. Alam DS, Yunus M, El Arifeen S, Chowdury HR, Larson CP, Sack DA et al. Zinc treatment for 5 or 10 days is equally efficacious in preventing diarrhea in the subsequent 3 months among Bangladeshi children. J Nutr 2011;141:312-5.

40. Larson CP, Koehlmoos TP, Sack DA; Scaling Up of Zinc for Young Children (SUZY) Project Team. Scaling up zinc treatment of childhood diarrhoea in Bangladesh: theoretical and practical considerations guiding the SUZY Project. Health Policy Plan 2012;27:102-14.

41. Lindström E, Hossain MB, Lönnerdal B, Raqib R, El Arifeen S, Ekström EC. Prevalence of anemia and micronutrient deficiencies in early pregnancy in rural Bangladesh, the MINIMat trial. Acta Obstet Gynecol Scand 2011;90:47-56.

42. Jiang T, Christian P, Khatry SK, Wu L, West KP, Jr. Micronutrient deficiencies in early pregnancy are common, concurrent, and vary by season among rural Nepali pregnant women. J Nutr 2005;135:1106-12.

43. Parajuli RP, Umezaki M, Watanabe C. Diet among people in the Terai region of Nepal, an area of micronutrient deficiency. J Biosoc Sci 2012;44:401-15.

44. Christian P, Jiang T, Khatry SK, LeClerq SC, Shrestha SR, West KP, Jr. Antenatal supplementation with micronutrients and biochemical indicators of status and subclinical infection in rural Nepal. Am J Clin Nutr 2006;83:788-94.

45. Tielsch JM, Khatry SK, Stoltzfus RJ, Katz J, LeClerq SC, Adhikari R et al. Effect of daily zinc supplementation on child mortality in southern Nepal: a communitybased, cluster randomised, placebo-controlled trial. Lancet 2007;370:1230-9.

46. Tielsch JM, Khatry SK, Stoltzfus RJ, Katz J, LeClerq SC, Adhikari R et al. Effect of routine prophylactic supplementation with iron and folic acid on preschool child mortality in southern Nepal: communitybased, cluster-randomised, placebo-controlled trial. Lancet 2006;367:144-52.

47. Christian P, Shrestha J, LeClerq SC, Khatry SK, Jiang $\mathrm{T}$, Wagner T, et al. Supplementation with micronutrients in addition to iron and folic acid does not further improve the hematologic status of pregnant women in rural Nepal. J Nutr 2003;133:3492-8.

48. Christian P, Darmstadt GL, Wu L, Khatry SK, LeClerq SC, Katz J et al. The effect of maternal micronutrient supplementation on early neonatal morbidity in rural Nepal: a randomised, controlled, community trial. Arch Dis Child 2008;93:660-4.

49. Kumar P, Lal NR, Mondal AK, Mondal A, Gharami RC, Maiti A. Zinc and skin: a brief summary. Dermatol Online J 2012;18:1.

50. de Benoist B, Darnton-Hill I, Davidsson L, Fontaine 
O, Hotz C. Conclusions of the Joint WHO/UNICEF/ IAEA/IZiNCG Interagency Meeting on Zinc Status Indicators. Food Nutr Bull 2007;28(Suppl 3):S480-4.

51. Gibson RS, Anderson VP. A review of interventions based on dietary diversification or modification strategies with the potential to enhance intakes of total and absorbable zinc. Food Nutr Bull 2009;30(Suppl 1):S108-43.

52. Lönnerdal B. Dietary factors influencing zinc absorption. J Nutr 2000;130(Suppl 5S):1378S-83S.

53. Davidsson L, Ziegler EE, Kastenmayer P, van Dael P, Barclay D. Dephytinisation of soyabean protein isolate with low native phytic acid content has limited impact on mineral and trace element absorption in healthy infants. Br J Nutr 2004;91:287-94.

54. Egli I, Davidsson L, Zeder C, Walczyk T, Hurrell R. Dephytinization of a complementary food based on wheat and soy increases zinc, but not copper, apparent absorption in adults. J Nutr 2004;134:1077-80.

55. Kim EY, Pai TK, Han O. Effect of bioactive dietary polyphenols on zinc transport across the intestinal Caco-2 cell monolayers. J Agric Food Chem 2011;59:3606-12.

56. World Health Organization. Trace elements in human nutrition and health. Geneva: World Health Organization, 1996. $361 \mathrm{p}$.

57. Institute of Medicine, Food and Nutrition Board. Dietary reference intakes for vitamin A, vitamin $\mathrm{K}$, arsenic, boron, chromium, copper, iodine, iron, manganese, molybdenum, nickel, silicon, vanadium, and zinc. Washington, DC: National Academy Press, 2001. 28 p.

58. Donangelo CM, Zapata CL, Woodhouse LR, Shames DM, Mukherjea R, King JC. Zinc absorption and kinetics during pregnancy and lactation in Brazilian women. Am J Clin Nutr 2005;82:118-24.

59. Gibson RS. Strategies for preventing micronutrient deficiencies in developing countries. Asia Pac J Clin Nutr 2004;13(Suppl):S23.

60. Berni Canani R, Buccigrossi V, Passariello A. Mechanisms of action of zinc in acute diarrhea. Curr Opin Gastroenterol 2011;27:8-12.

61. Hooda PS, Henry CJ, Seyoum TA, Armstrong LD, Fowler MB. The potential impact of soil ingestion on human mineral nutrition. Sci Total Environ 2004;333:75-87.

62. Black RE. Zinc deficiency, infectious disease and mortality in the developing world. J Nutr 2003;133(Suppl 1):1485S-9S.

63. Black RE, Sazawal S. Zinc and childhood infectious disease morbidity and mortality. Br J Nutr 2001;85 (Suppl 2):S125-9.
64. Akhtar S. Food safety challenges-a Pakistan's perspective. Crit Rev Food Sci Nutr 2012 (DOI:10.1080/1 0408398.2011.650801).

65. Akhtar S, Sarker MR, Hossain A. Microbiological food safety - a dilemma of developing societies. Crit Rev Microbiol 2013 (DOI:10.3109/1040841X. 2012.742036).

66. Fischer Walker CL, Black RE. Functional indicators for assessing zinc deficiency. Food Nutr Bull 2007;28(Suppl 3):S454-79.

67. Brown KH, Peerson JM, Rivera J, Allen LH. Effect of supplemental zinc on the growth and serum zinc concentrations of prepubertal children: a meta-analysis of randomized controlled trials. Am J Clin Nutr 2002;75:1062-71.

68. World Health Organization. World Health Report 2002: reducing risks, promoting healthy life. Geneva: World Health Organization, 2002:7-14.

69. Ezzati M, Lopez AD, Rodgers A, Vander Hoorn S, Murray CJ; Comparative Risk Assessment Collaborating Group. Selected major risk factors and global and regional burden of disease. Lancet 2002;360:1347-60.

70. Black R. Micronutrient deficiency-an underlying cause of morbidity and mortality. Bull World Health Organ 2003;81:79.

71. Akhtar S, Anjum FM, Rehman ZU, Riaz M, Arshad M, Basit A et al. Effect of zinc and iron fortification of the feed on liver and thyroid function in rats. Biol Trace Elem Res 2011;144:894-903.

72. Brown KH, Peerson JM, Baker SK, Hess SY. Preventive zinc supplementation among infants, preschoolers, and older prepubertal children. Food Nutr Bull 2009;30(Suppl 1):S12-40.

73. Baqui AH, Black RE, El Arifeen S, Yunus M, Chakraborty J, Ahmed S et al. Effect of zinc supplementation started during diarrhoea on morbidity and mortality in Bangladeshi children: community randomised trial. BMJ 2002;325:1059.

74. Brooks WA, Yunus M, Santosham M, Wahed MA, Nahar K, Yeasmin S et al. Zinc for severe pneumonia in very young children: double-blind placebo-controlled trial. Lancet 2004;363:1683-8.

75. Mahalanabis D, Lahiri M, Paul D, Gupta S, Gupta A, Wahed MA et al. Randomized, double-blind, placebocontrolled clinical trial of the efficacy of treatment with zinc or vitamin A in infants and young children with severe acute lower respiratory infection. Am J Clin Nutr 2004;79:430-6.

76. Brown KH, Hambidge KM, Ranum P; Zinc Fortification Working Group. Zinc fortification of cereal flours: current recommendations and research needs. Food Nutr Bull 2010;31(Suppl 1):S62-74. 
77. Allen L, de Benoist B, Dary O, Hurrell R, editors. Guidelines on food fortification with micronutrients. Geneva: World Health Organization, 2006. 341 p.

78. World Health Organization, Regional Office for the Eastern Mediterranean. Fortification of flour to control micronutrient deficiencies in the Eastern Mediterranean Middle East and North Africa: report of a joint WHO/UNICEF/MI/ILSI workshop. Alexandria: Regional Office for the Eastern Mediterranean, World Health Organization, 1999. 137 p.

79. Harvest Plus. Harvest Plus research and implementation: breeding crops for better nutrition. Washington, DC: Harvest Plus. 2 p. (http://r4d.dfid.gov.uk/PDF/ Outputs/Misc_Crop/hpRIbrochure.pdf, accessed on 27 May 2013).
80. Temple L, Gibson RS, Hotz C. Use of soaking and enrichment for improving the content and bioavailability of Calcium, Iron, and Zinc in complementary foods and diets of rural Malawian weanlings. J Food Sci 2002;67:1926-32.

81. Hambidge KM, Huffer JW, Raboy V, Grunwald GK, Westcott JL, Sian L et al. Zinc absorption from lowphytate hybrids of maize and their wild-type isohybrids. Am J Clin Nutr 2004;79:1053-9.

82. Gibson RS, Yeudall F, Drost N, Mtitimuni BM, Cullinan TR. Experiences of a community-based dietary intervention to enhance micronutrient adequacy of diets low in animal source foods and high in phytate: a case study in rural Malawian children. J Nutr 2003;133(Suppl 2):3992S-9S. 